\title{
Late reproductive senescence in a rabbit line hyper selected for reproductive longevity, and its association with body reserves
}

\author{
Per TheIlgaARD ${ }^{\mathrm{a} *}$, Juan Pablo SÁNCHEZ ${ }^{\mathrm{b}}$, Juan José PASCUAL ${ }^{\mathrm{a}}$, \\ Peer BERG ${ }^{\mathrm{c}}$, Nic C. FRIGGENS ${ }^{\mathrm{c}}$, Manuel BASELGA ${ }^{\mathrm{a}}$ \\ ${ }^{a}$ Departamento de Ciencia Animal, Universidad Politécnica de Valencia, Spain \\ ${ }^{\mathrm{b}}$ Departamento de Producción Animal I, Universidad de León, Spain \\ ${ }^{c}$ Danish Institute of Agricultural Sciences, Research Centre Foulum, PO-Box 50, \\ DK-8830 Tjele, Denmark
}

(Received 29 March 2006; accepted 16 October 2006)

\begin{abstract}
The aim of the present study was to investigate differences in reproductive and body traits during successive parities between two genetic lines. The LP line was constituted by means of selection of animals having an extremely high number of parities (at least 25) and an average reproductive performance compared to the $\mathrm{V}$ line selected for litter size at weaning during 31 generations. The two lines were found to have an equal reproductive performance in the first three parities, but the LP line had higher reproductive performance from the fourth parturition onwards. The low reproductive performance after the third parity in the $\mathrm{V}$ line was suggested to be caused by constrained environmental conditions in the test station. A line by parity interaction was also observed for body weight, since body weight declined going from the third to the fourth parity in the LP line but not the V line. Thus, it was concluded that hyper selection for reproductive longevity and average prolificacy successfully delayed reproductive senescence, and that this newly founded line showed less environmental sensitivity, which might have been mediated by a higher body reserve.
\end{abstract}

rabbit females / longevity / reproductive performance / body fat / body weight

\section{INTRODUCTION}

Long living animals able to maintain a high rate of reproductive performance during successive lactations are of great interest in animal production to reduce the replacement cost of the animals and in terms of animal welfare. A new rabbit line with long reproductive lifespan, created by means of selection on animals having an extremely high number of parities and an average reproductive performance, was therefore constituted. The first generation of the

*Corresponding author: peth@dca.upv.es 
newly constituted line (the LP line) was found to have a longer reproductive life than a well documented line (the $\mathrm{V}$ line) selected during 31 generations solely on litter size at weaning $[26,27]$.

In aging and evolutionary research, it is common to find that survival and reproductive performance with age are related $[24,25,30]$. Consequently, it may be expected that the life time reproductive profiles of the above rabbit lines could have been affected by the selection criteria imposed. To our knowledge, only one earlier experiment has selected on reproductive longevity in mammals [14]. In that experiment, mice selected on reproductive longevity did not have different litter size than the control animals but the selected animals had a higher number of successful reproductive cycles. However, in a survival study involving the $\mathrm{V}$ line, it was found that selection on litter size did not decrease life span [33].

Body fatness, or condition of reproductive females is highly integrated with the reproductive pattern $[5,7,11]$ and survival opportunities $[33,34]$ of the animals. Selection for reproductive longevity has also been observed to increase body weight as a correlated effect (mice: [14]; vinegar flies: [15]). Thus, the increased longevity of the LP line might very well have been achieved by changes in the amount of fat in the body, and the dynamic of storing and mobilisation of body reserves during the reproductive cycle.

The overall aim of this work was to investigate the parity dependent relationship between reproduction and body traits for a rabbit line hyper selected for reproductive longevity and average prolificacy relative to a well described prolific line. Two expectations were tested; first, that the prolific line would have more intense early reproductive performance but poorer performance later on, compared with the LP line. Second, the size and use of body reserves in support of lactation and gestation will evolve with parity in a similar pattern as that of the reproductive performance.

\section{MATERIALS AND METHODS}

The experiment was performed at the test station of the Department of Animal Science of Polytechnic University of Valencia, Spain. The animals entered the experiment between October 2004 and March 2005 and the data collected until the end of February 2006 was used in the present work.

\subsection{Animals}

A total of 246 reproductive rabbits were used in the experiment. One hundred and eighteen does were from the 31st generation of the $\mathrm{V}$ line selected 
for litter size at weaning by BLUP methodology using a repeatability animal model [4]. In this line, each generation consisted of 120 females and 25 bucks and reproductive management involved non-overlapping generations. Animals were bred and reared in a building that has an insulated roof and walls, controlled lighting and ventilations, and a cooling system to prevent extreme temperatures in the summer. The average number of parities is around 3.6. The population structure and the selection procedure of the $\mathrm{V}$ line have previously been described in detail [8]. One hundred and twenty-eight animals were from the newly constituted LP line, founded by selection of animals having at least 25 parities and an average litter size of at least 7.5 pups born alive. For comparison, in rabbit production systems in Spain, the average number of parturitions for a doe is around 6 and the average number born is 9 [20]. The selection pressure was assumed to be two to five selected does for each thousand. The LP line was constituted through three scannings of production farms on the Iberian Peninsula for females following the selection criteria. The first scanning was done in April 2002, where 15 animals from 8 different farms were chosen and brought to the test station. These females were inseminated with semen from males of at that time, current generation of the V line. Twelve of the $15 \mathrm{fe}$ males gave birth to males. The second scanning was done in September and November 2002, where another 15 females from 10 different farms were selected. These females were inseminated with semen from males produced in the first round, resulting in 17 male offspring from 11 of the 15 collected females. The last scanning was done between June and November 2003, where 32 does matching the criteria of longevity and litter size performance were collected, and mated to males from the second round of selection. Thirty of these females gave birth to offspring, which were considered to be the generation 0 of the long-living productive line, hereafter referred to as the LP line, consisting of 42 females and 32 males. This generation was multiplied by random mating in order to create the population used in the present experiment. This newly founded line had better survival properties than the V line, and the litter size of the LP line was significantly lower than the first three parities of the $\mathrm{V}$ line, whereas no line difference in litter size was found from the fourth parity onwards $[26,27]$. The LP line was also found to have higher feed intake, higher milk yield and higher concentration of plasma non-esterified fatty acids (an indicator of mobilisation) compared to the V line [32]. Since genetic characteristics of the commercial farms where the LP does were selected are not registered, the differences between the lines cannot definitely be attributed to the different selection programmes. However, since the two lines are extreme 
selected in different directions, the comparison is of value to understand the relationship between reproduction, longevity and body reserves.

\subsection{Management and measured traits}

Rabbits were kept in individual cages throughout the experiment. Lactating does received a standard commercial diet ad libitum whereas non-lactating does were feed restricted to prevent excessive fattening. Females were first presented to a male at 4.5 months of age, and subsequently at day 25 postpartum in each lactation. Females not accepting the male were presented to the same male the following week. The only culling reasons were lack of pregnancy after 3 successful matings, or if she refused the male in six consecutive presentations. Litters were not standardised and the doe had free access to the nest during the whole lactational period. Number born alive (NBA) and number born in total (NBT) were recorded at parturition. The individual weight of each offspring was measured at weaning (day 28). The individual offspring weights were added within each litter to calculate the litter weight at weaning (LWW).

In a subset of the rabbits ( $72 \mathrm{~V}$ and $59 \mathrm{LP}$ does), we also measured litter weight at birth (LWB) of kits born alive. In these does, perirenal fat thickness and body weight of females were measured on days 1,10 and 25 in lactation. These days were chosen since they have different interpretations; day 1 reflects body state at parturition, thereafter the body reserves increase and are at the highest level around day 10 [19], and this day is therefore expected to reflect the amount of body resources available for the rest of the lactational period. The day 25 measurement reflects the body state after the period with high lactational demand, and this day also corresponds to the day of mating. The observations were done on fixed weekdays. Thus, the day 1 measurement was done on Tuesdays, the day after expected parturition. The day 10 and 25 measurements were done on the Friday in the second and fourth week in lactation, respectively. The perirenal fat thickness was measured by use of ultrasound using a Justvision 200 "SSA-320A", Toshiba, as described by Pascual et al. [16], and the average perirenal fat thickness of the left and right side of the back was used for further calculations.

\subsection{Statistical analysis}

All traits having one observation per parity were analysed with a repeatability model including fixed effect of line (LP, V), parity $(1,7)$ and the line by 
parity interaction. The parity effect was to a large extent confounded with the year-season effect and therefore no significance indication was given for this effect. The difference between lines relative to parity was of central interest in this work, and the interaction parity by line was therefore included in all analyses, independent of its significance. Random effects included non-additive plus permanent environmental effects, the additive genetic effect and residual error.

Body weight and perirenal fat thickness with repeated measures during lactation were analysed with a model similar to the above, but extended with a fixed effect of stage in lactation in three levels (day 1, day 10 and day 25). Preliminary analysis using a repeatability model performed with the mixed procedure implemented in the SAS ${ }^{\circledR}$ package was performed to choose which effects to include in the final model. Up to three-way interactions were included in the base model, and effects found non-significant were step-wise excluded. The three-way interactions and the line by stage in lactation effects were not found to be significant for either body weight or perirenal fat thickness. Thus, the final model for perirenal fat thickness and body weight included the following fixed effects; genetic line (LP, V), parity $(1,7)$, stage in lactation (day 1 , day 10 , day 25) and the interactions parity by stage in lactation and parity by line. Random effects included non-additive plus permanent environmental effects, their additive genetic effect and residual error.

The mixed model equations were solved using genetic parameters from the literature. The heritabilities used for NBT, NBA and NW were $0.10,0.07$ and 0.05 and the ratio of non-additive plus permanent environmental effects of the doe to phenotypic variance were assumed to be $0.12,0.10$ and 0.08 [8]. For LWB and LWW, a heritability value of 0.15 was used and the corresponding ratio of non-additive plus permanent environmental to phenotypic variance effects was set at 0.05 . For perirenal fat thickness and body weight, heritabilities of 0.30 and 0.25 and variance ratios of 0.1 and 0.15 were used.

The generalised least squares estimates of fixed effects and contrasts were calculated using the PEST package [10]. Significance was claimed when the probability value was below 0.05 . Pedigree information included information on the females and their parents.

\section{RESULTS}

\subsection{Reproductive traits}

The effects included in the model for each trait and their significance levels are shown in Table I. Total number born was affected by a line by parity interaction (Fig. 1). This consisted of a similar reproductive performance between 
Table I. Probability value for each of the fixed effects included in the model for each trait analysed.

\begin{tabular}{lrrrcc}
\hline Trait $^{\mathrm{a}}$ & Line & Parity & Line $\times$ parity & $\begin{array}{c}\text { Stage } \\
\text { in lactation }\end{array}$ & $\begin{array}{c}\text { Parity } \times \text { stage } \\
\text { in lactation }\end{array}$ \\
\hline Number born total & $0.062<0.001$ & 0.001 & - & - \\
Number born alive & $0.190<0.001$ & 0.025 & - & - \\
Litter weight at birth & $0.163<0.001$ & 0.281 & - & - \\
Number weaned & $0.153<0.001$ & 0.079 & - & - \\
Litter weight at weaning & $<0.001<0.001$ & 0.383 & - & - \\
BW & $0.017<0.001$ & $<0.001$ & $<0.001$ & 0.007 \\
PFT & $0.589<0.001$ & 0.302 & $<0.001$ & $<0.001$ \\
dPFT (day 10 - day 1) & $0.082<0.001$ & 0.125 & - & - \\
dPFT (day 10 - day 25) & 0.911 & 0.031 & 0.023 & - & - \\
\hline
\end{tabular}

${ }^{\mathrm{a}} \mathrm{BW}=$ body weight; PFT = perirenal fat thickness; dPFT refer to difference in perirenal fat thickness between the two days indicated in parenthesis.

lines during the first three parities (LP-V: $-0.1 \pm 0.13 ; P=0.41$ ) but thereafter the reproductive performance for the $\mathrm{V}$ line declined more than that of the LP line, and the LP line had a significantly higher reproductive performance from the fourth lactation onwards (LP-V: $0.61 \pm 0.19 ; P<0.001)$. The same pattern appeared for number born alive (results not shown) and to a lesser extent for number weaned. No interaction between line and parity was detected for litter weight at birth or at weaning (Tab. I).

\subsection{Body weight and perirenal fat thickness}

Body weight was also significantly $(P<0.001)$ affected by the interaction between line and parity as the body weight decreased between the third and fourth lactation for the LP line, but a similar decline was not observed for the $\mathrm{V}$ line (Fig. 2). The LP line was overall significantly heavier $(+0.15 \pm$ $0.04 \mathrm{~kg}$ ) than the $\mathrm{V}$ line (Tab. III). Body weight was also significantly $(P<$ 0.01 ) affected by a parity by stage in lactation interaction (Fig. 3). The body weight at day 1 and day 10 followed the same trajectory with parity, whereas the day 25 body weight differed from this trajectory, having relative lower values in the third and fourth parity. Even so, there was an overall effect of stage in lactation (Tab. III); the lowest body weight was observed at day 1 of lactation $(4.09 \pm 0.02 \mathrm{~kg})$, increased to day $10(4.29 \pm 0.02 \mathrm{~kg})$ and then declined to day $25(4.21 \pm 0.02 \mathrm{~kg})$.

The interaction between line and parity was not significant for the perirenal fat thickness (Tab. I), and no significant line difference for perirenal fat 

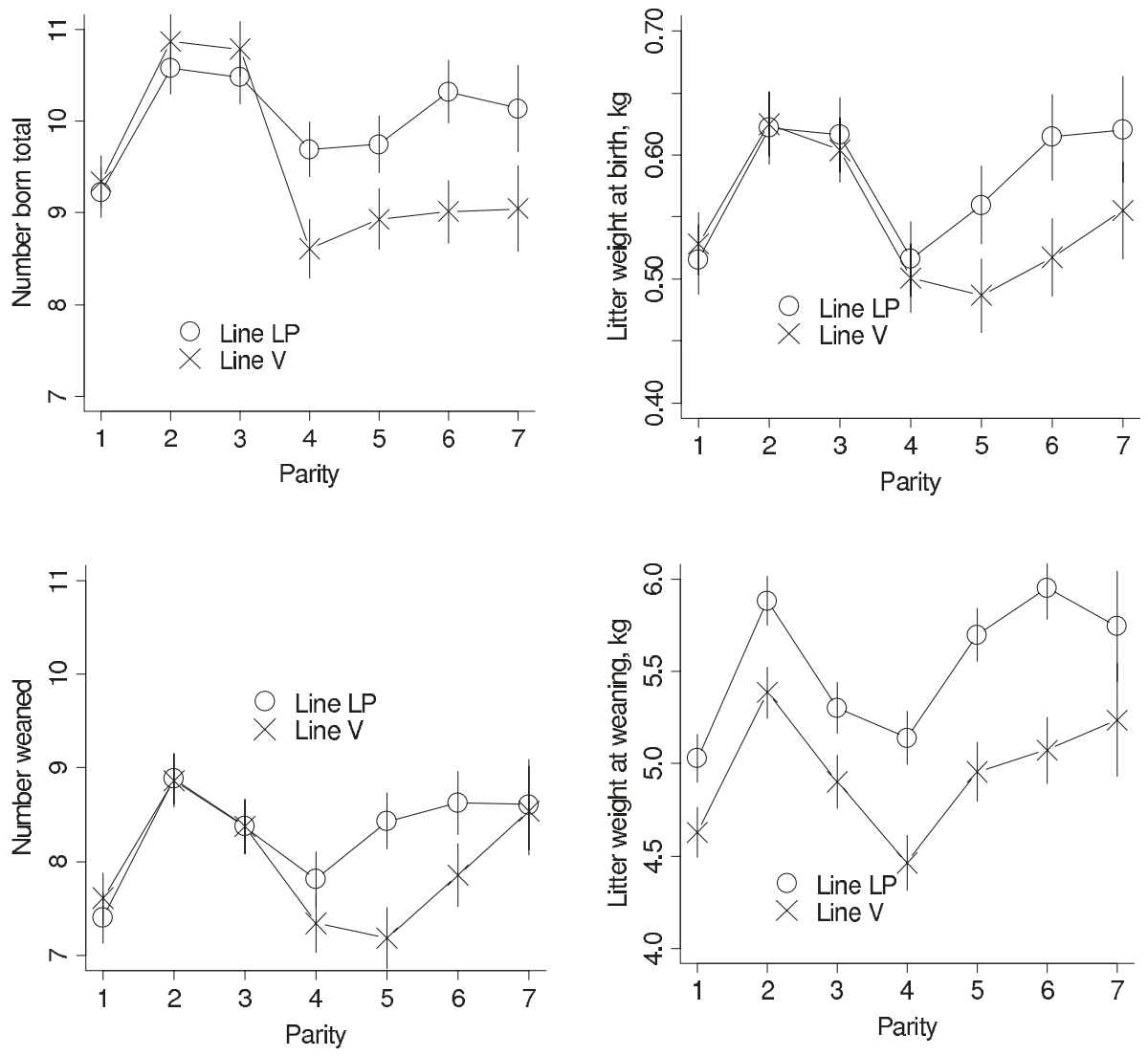

Figure 1. Mean values of litter size traits during seven parities for the LP and V line. Error bars show $+/-$ one standard error.
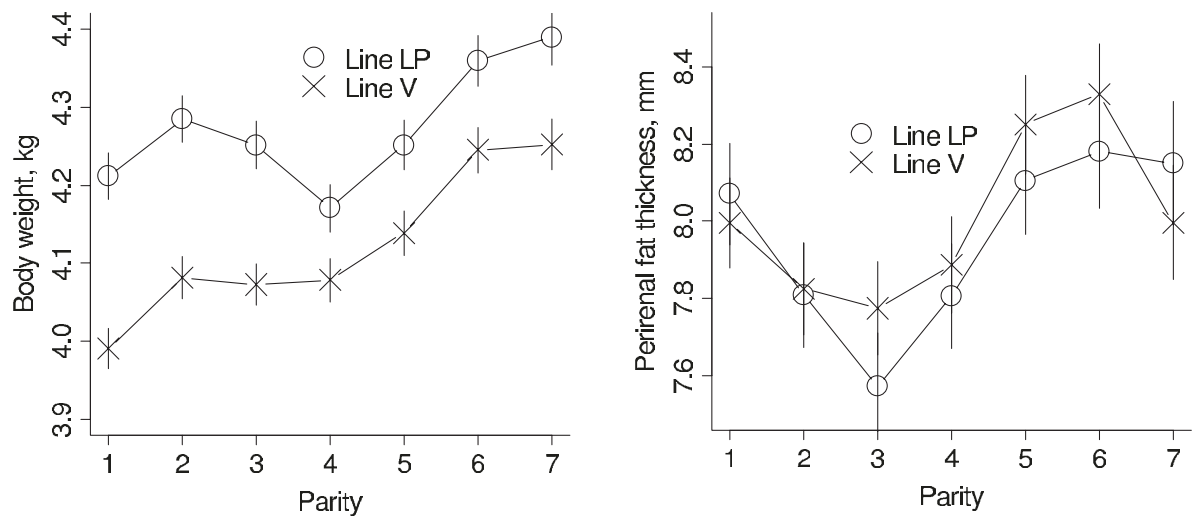

Figure 2. Mean body weight and perirenal fat thickness during seven parities for the LP and V lines. Error bars show $+/-$ one standard error. 

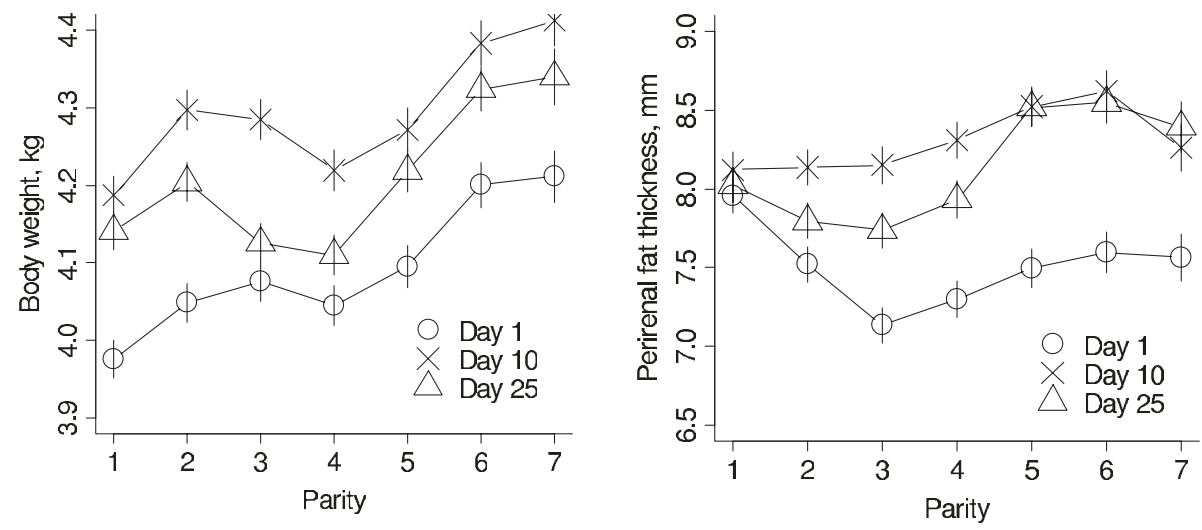

Figure 3. Mean body weight and perirenal fat thickness for three stages in lactation during seven parities. Each symbol corresponds to a measurement taken at day 1, day 10 or day 25 . Error bars show $+/-$ one standard error.

Table II. Least squares means and standard errors for reproductive traits for the LP line selected on reproductive longevity and average prolificacy and the V selected on prolificacy. The effect of parity is also shown.

\begin{tabular}{|c|c|c|c|c|c|c|c|c|c|c|c|}
\hline \multirow[t]{2}{*}{ Trait $^{\mathrm{c}}$} & & \multicolumn{2}{|c|}{ NBT } & \multicolumn{2}{|c|}{ NBA } & \multicolumn{2}{|c|}{ NW } & \multicolumn{2}{|c|}{ LWB } & \multicolumn{2}{|c|}{ LWW } \\
\hline & & $\mathrm{n}$ & s.e. & $\mathrm{n}$ & s.e. & $\mathrm{n}$ & s.e. & $\mathrm{kg}$ & s.e. & $\mathrm{kg}$ & s.e. \\
\hline \multicolumn{12}{|l|}{ Line } \\
\hline & LP & $10.02^{\mathrm{e}}$ & 0.19 & $9.43^{\mathrm{a}}$ & 0.19 & $8.30^{\mathrm{a}}$ & 0.16 & $0.58^{\mathrm{a}}$ & 0.02 & $5.54^{\mathrm{a}}$ & 0.10 \\
\hline & $\mathrm{V}$ & $9.51^{\mathrm{a}}$ & 0.20 & $9.05^{\mathrm{a}}$ & 0.20 & $7.97^{\mathrm{a}}$ & 0.17 & $0.55^{\mathrm{a}}$ & 0.02 & $4.95^{\mathrm{b}}$ & 0.10 \\
\hline \multicolumn{12}{|c|}{ Parity $^{\mathrm{d}}$} \\
\hline & 1 & 9.28 & 0.20 & 8.88 & 0.21 & 7.50 & 0.19 & 0.52 & 0.02 & 4.83 & 0.09 \\
\hline & 2 & 10.72 & 0.20 & 10.21 & 0.21 & 8.88 & 0.19 & 0.62 & 0.02 & 5.64 & 0.10 \\
\hline & 3 & 10.64 & 0.21 & 9.91 & 0.22 & 8.37 & 0.20 & 0.61 & 0.02 & 5.10 & 0.10 \\
\hline & 4 & 9.15 & 0.22 & 8.56 & 0.23 & 7.58 & 0.21 & 0.51 & 0.02 & 4.80 & 0.10 \\
\hline & 5 & 9.34 & 0.23 & 8.99 & 0.24 & 7.81 & 0.24 & 0.52 & 0.02 & 5.33 & 0.11 \\
\hline & 6 & 9.67 & 0.24 & 9.12 & 0.26 & 8.24 & 0.24 & 0.57 & 0.02 & 5.51 & 0.12 \\
\hline & 7 & 9.59 & 0.33 & 8.99 & 0.36 & 8.57 & 0.34 & 0.59 & 0.03 & 5.49 & 0.21 \\
\hline
\end{tabular}

ab Levels of factor not sharing the same superscript within fixed effect and column indicate significant differences $(P<0.05)$.

c Abbreviations used: NBT: Number Born Total, NBA: Number Born Alive, NW: Number Weaned, LWB: Litter Weight at Birth, LWW: Litter Weight at Weaning.

${ }^{\mathrm{d}}$ Parity was confounded with year-season, thus, no contrast test between parities was performed for this effect.

${ }^{\mathrm{e}}$ Line difference found on probability value $P=0.06$. 
Table III. Least squares means and standard errors of body weight and perirenal fat thickness for the LP line selected on reproductive longevity and average prolificacy and the $\mathrm{V}$ line selected on prolificacy, parity and stage in lactation.

\begin{tabular}{lccccc}
\hline Trait & \multicolumn{3}{c}{$\begin{array}{c}\text { Body weight } \\
\mathrm{kg}\end{array}$} & \multicolumn{2}{c}{ Perirenal fat thickness } \\
& & & & & \\
Gmetic line & $\mathrm{LP}$ & $4.27^{\mathrm{a}}$ & 0.03 & $7.96^{\mathrm{a}}$ & 0.12 \\
& $\mathrm{~V}$ & $4.12^{\mathrm{b}}$ & 0.02 & $8.01^{\mathrm{a}}$ & 0.11 \\
\hline Parity $^{\mathrm{d}}$ & & & & & \\
& 1 & 4.10 & 0.02 & 8.03 & 0.09 \\
& 2 & 4.18 & 0.02 & 7.82 & 0.09 \\
& 3 & 4.16 & 0.02 & 7.67 & 0.09 \\
& 4 & 4.12 & 0.02 & 7.85 & 0.09 \\
& 5 & 4.20 & 0.02 & 8.18 & 0.10 \\
& 6 & 4.30 & 0.02 & 8.26 & 0.10 \\
& 7 & 4.32 & 0.02 & 8.07 & 0.11 \\
\hline Stage in lactation & & & & & \\
& Day 1 & $4.09^{\mathrm{a}}$ & 0.02 & $7.51^{\mathrm{a}}$ & 0.09 \\
& Day 10 & $4.29^{\mathrm{b}}$ & 0.02 & $8.30^{\mathrm{b}}$ & 0.09 \\
& Day 25 & $4.21^{\mathrm{c}}$ & 0.02 & $8.14^{\mathrm{c}}$ & 0.09 \\
\hline
\end{tabular}

abc Levels of factor not sharing the same superscript within fixed effect and column indicate significant differences $(P<0.05)$.

${ }^{\mathrm{d}}$ Parity was confounded with year-season, thus, no contrast test between parities was performed for this effect.

thickness was observed (LP: $7.96 \pm 0.12 \mathrm{~mm}$; V: $8.01 \pm 0.11 \mathrm{~mm}$; Tabs. I and III). Perirenal fat thickness was significantly affected by parity, consisting in an overall decrease during the first three parities, followed by an increase in the later parities (Fig. 2). However, perirenal fat thickness was also affected by a stage in lactation by parity effect. Thus, the overall decrease during the first three parities is mainly because of lower perirenal fat thickness at day 1 , whereas the day 10 and day 25 perirenal fat thickness changed less with parity (Fig. 3).

The deposition of fat reserves was calculated as the gain in perirenal fat thickness from day 1 to day 10. Fat deposition was significantly affected by parity, increasing during the first three lactations after which no change was observed between the remaining parities (Tab. IV). The deposition of fat reserves increased more for the LP line during the first three lactations, and the deposition was significantly higher in the third parity $(+0.59 \pm 0.28 \mathrm{~mm}$; Fig. 4). In the remaining parities, no line differences were observed. The mobilisation of 
Table IV. Least squares means and standard errors of change in perirenal fat thickness between days 1 and 10 and between days 10 and 25 for the LP line selected on reproductive longevity and average prolificacy and the $\mathrm{V}$ line selected on prolificacy.

\begin{tabular}{|c|c|c|c|c|c|}
\hline \multirow[t]{2}{*}{ Trait } & & \multicolumn{2}{|c|}{$\begin{array}{l}\text { Perirenal fat thickness } \\
\text { day } 10 \text { minus day } 1\end{array}$} & \multicolumn{2}{|c|}{$\begin{array}{l}\text { Perirenal fat thickness } \\
\text { day } 10 \text { minus day } 25\end{array}$} \\
\hline & & $\mathrm{mm}$ & s.e. & $\mathrm{mm}$ & s.e. \\
\hline \multicolumn{6}{|l|}{ Line } \\
\hline & LP & $0.89^{\mathrm{a}}$ & 0.15 & $0.19^{\mathrm{a}}$ & 0.16 \\
\hline & $\mathrm{V}$ & $0.73^{\mathrm{a}}$ & 0.14 & $0.17^{\mathrm{a}}$ & 0.14 \\
\hline \multicolumn{6}{|c|}{ Parity $^{b}$} \\
\hline & 1 & 0.17 & 0.13 & 0.12 & 0.14 \\
\hline & 2 & 0.64 & 0.14 & 0.33 & 0.14 \\
\hline & 3 & 1.09 & 0.14 & 0.45 & 0.15 \\
\hline & 4 & 1.01 & 0.14 & 0.39 & 0.15 \\
\hline & 5 & 1.04 & 0.15 & 0.01 & 0.16 \\
\hline & 6 & 0.99 & 0.16 & 0.04 & 0.17 \\
\hline & 7 & 0.74 & 0.18 & -0.08 & 0.20 \\
\hline
\end{tabular}

${ }^{a}$ Levels of factor not sharing the same superscript within fixed effect and column indicate significant differences $(P<0.05)$.

${ }^{\mathrm{b}}$ Parity was confounded with year-season, thus, no contrast test was performed for this effect.
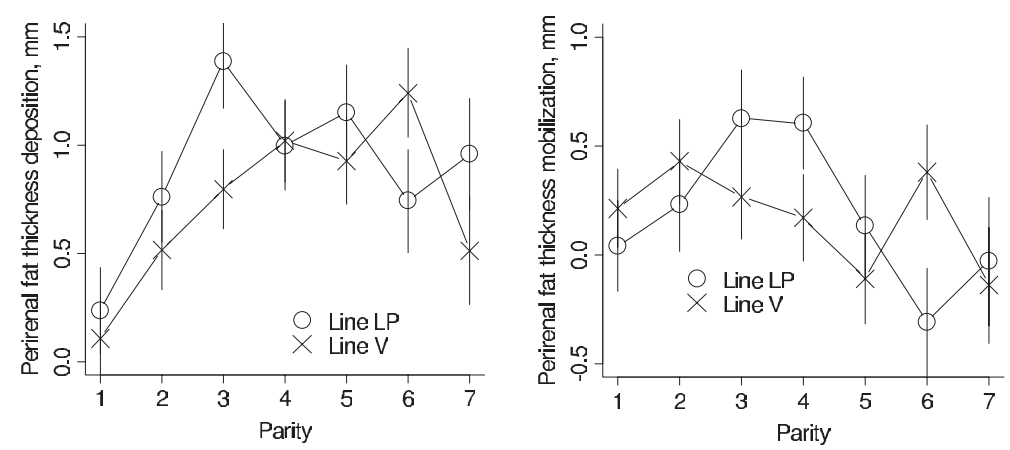

Figure 4. Mean fat deposition (day 10 minus day 1 values) and mobilisation (day 10 minus day 25 values) of perirenal fat thickness. Error bars show $+/-$ one standard error.

fat reserves was calculated as the difference in perirenal fat thickness between day 10 and day 25 and was significantly affected by a line by parity interaction (Fig. 4). This interaction indicated that the mobilisation declined earlier in life for the $\mathrm{V}$ line compared to the LP line. The mobilisation of fat reserves was not found to be significantly different between lines for any parity, with the exception of the sixth parity, where the $\mathrm{V}$ line had a higher $(+0.68 \pm 0.33 \mathrm{~mm})$ mobilisation, a fact that also contributed to the mentioned interaction. 


\section{DISCUSSION}

\subsection{Effect of line and parity on reproductive performance}

Earlier reproductive senescence for the prolific V line compared with the LP line was observed for all reproductive traits investigated, though not all were significant (Fig. 1; Tab. I). The maximum reproductive performance was in the second and third parity, in agreement with the literature [1,31], after which the reproductive performance declined for both lines, but most pronouncedly for the $\mathrm{V}$ line. The dramatic decline in litter size after the third parity was unexpected. In earlier generations of the $\mathrm{V}$ line, this dramatic decline in reproductive output between third and fourth parturition was not observed (results not shown). Neither was this dramatic decline observed in a larger scale test comparing the same two rabbit lines on two other test stations [26], even though this experiment was running in the same time period. In that test, the V line was found to have significant higher litter size in the first three parities, whereas no line difference was observed at later parities. Because of the unexpected and unusual results in the present experiments in comparison with earlier generations of the $\mathrm{V}$ line and the larger scale experiments [26], we therefore speculated as to what might have happened in the present experiment that caused the difference.

One possible explanation for the dramatic decline in reproductive performance for the $\mathrm{V}$ line is that it could be a sire effect, but since sires were used across parities and since the interval between parturitions did not differ between lines [26], this explanation does not hold. Another possible explanation relates to environmental temperature. In the present experiment, animals entered the experiment between October 2004 and March 2005. Consequently, the time period where the majority of the animals reached the third or fourth parity corresponded to the hot summer period (July and August). It has been shown that high environmental temperature can depress intake and reproduction [13], and the decline in reproductive performance with parity might therefore be more pronounced than if the parturitions were equally spread over the year. However, the decline in reproduction performance for the $\mathrm{V}$ line seemed to act independently of the season of the year, as was observed for parturitions falling both before (May) and as well as during (July and August) the hot season. Moreover, the effect was largely on fourth parity, since the third parturitions in the same period performed well even in the hot season (distributions of parities with calendar year not shown). Thus, it seems unlikely that temperature alone can explain the observed decline in reproductive performance in our experiment. A third possible explanation could involve management in 
the test station. The management was temporarily changed as a means to standardise the management procedures with the two other farm units for a large scale comparison of the two genetic lines. On the test station where the present results are produced, the changes consisted in mating the dams at day 25 of lactation instead of day 11. Consequently, the time period between weaning and the following parturition was increased. During this weaning to parturition period, as a standard procedure on the test station, the dams were feed restricted. This management is different to the two other farm units, where animals were kept on lactational feed ad libitum during the whole reproductive life span. Thus, the extended period on restricted feed might have prevented the animals on the test station from fully expressing their genetic reproductive potential.

Whatever the exact nature of the environmental challenge, the combination of results from the present experiment, together with the other evidence [26] described above, indicates that under good/normal environmental conditions, reproductive output did not show a trade-off between early reproduction and late life reproduction, but under restricted environmental conditions in the present experiment, the pattern observed for reproductive output did show evidence in support of trade-offs e.g. $[12,24,25]$ between early and late fitness, where fitness in this case was reproduction. It is common to find that trade-offs are more easily detected under poor than good environmental conditions $[23,29]$. We are only aware of one other experiment selecting on reproductive longevity [14]. In that experiment, mice selected for reproductive longevity did not differ in reproductive performance early in life compared with a control group, but had a more persistent reproduction in late life. Our results suggest that there are different genes involved first and later in life, and thereby the genetic relationship between successive parities. In the present study, we did not have a sufficient number of animals to estimate the correlation between parities, but in a recent study it was reported that three lines of rabbit all selected for litter size at weaning had a different genetic correlation between parities [17]. Since the animals in the present work were selected for more distinct traits, the difference in correlation between parities can be expected to be greater.

\subsection{Effect of line and parity on temporal pattern in body traits across parity during lactation}

Both reproduction and maintenance (survival) are energetically expensive, and mammals have evolved the adaptation of using body reserves in support of 
reproduction [7]. We therefore used body weight and perirenal fat thickness as indicators of how the rabbits prioritise their energy reserves. The LP line was heavier than the $\mathrm{V}$ line throughout life, in agreement with experiments where selecting on reproductive longevity in mice [14] and selecting on late reproduction in vinegar flies [15] also increased body weight. This suggests that selection for longer life favours extended growth to produce a more durable adult soma, in accordance with the evolutionary theories [24,25].

Body weight was affected by a line by parity interaction, consisting of a decline in body weight between the third and fourth parity for the LP line but not for the V line (Fig. 3). The observed line by parity interaction for body weight in combination with the observed interaction in reproductive performance described above indicates that the two lines responded differently to the environmental challenge; the V line decreased reproduction dramatically but maintained body weight, whereas the LP line decreased body weight and maintained the reproduction. This suggests that the lines have evolved different priorities/possibilities as a consequence of different selection. Thus, the $\mathrm{V}$ line might not have had sufficient reserves to meet an environmental challenge without negative consequences on reproduction, whereas the LP line had more abundant resources to sustain a decline in body weight, which could eventually be recovered later. According to Beilharz and co-workers [2], selection in domesticated animals causes allocation of more resources to the traits selected. Even if the total amount of resources available steadily increases with selection, there will be a lesser proportion of resources available for the traits not selected for. The severe decline in reproductive performance for the $\mathrm{V}$ line relative to the LP line suggests that selection for reproductive performance was achieved at the expense of investment in usable body reserves, and this line had no extra resources available when an environmental challenge occurred.

We investigated if this pattern could be detected in the deposition and mobilisation of body reserves in support of lactation. For this purpose, we used the three measurements taken in each lactation (Fig. 3). Although there were no line differences in perirenal fat thickness across parities, there were within parity differences in the way body weight and perirenal fat thickness developed. Body weight at parturition increased during the first three parities, while perirenal fat thickness decreased in this period, indicating that the percent body fat during the first three parities decreased with age, in agreement with other studies [35]. To avoid confounding with growth, we used perirenal fat thickness and not body weight to investigate the effects on energy deposition and mobilisation. Fat deposition (day 10 minus day 1 values) increased across the first three lactations, mainly as a consequence of lower perirenal fat thickness 
at parturition (Fig. 4). Deposition increased more during the first three parities for the LP line than for the V line, whereas the pattern in later parities was unclear. The mobilisation of perirenal fat thickness, measured as the difference in perirenal fat thickness between day 10 and day 25, was affected by a line by parity interaction probably caused by different ranking of the lines along the parities (Fig. 4). The deposition and mobilisation pattern suggests that the $\mathrm{V}$ line used less body reserves to support lactation. This is contrary to other evidence signalling a positive relationship between deposition/mobilisation and reproduction e.g. mice [21], sows [9] and cows [18]. Also, in an earlier experiment on the same lines, it was shown that the $\mathrm{V}$ lines had a higher mobilisation (measured as a higher concentration in plasma non-esterified fatty acids) [32]. In that experiment, it was also found that the feed intake was significantly lower for the $\mathrm{V}$ line, which also makes it more difficult for this line to recover body reserves.

A lower body buffer capacity has also been indicated in other studies, e.g. selection for litter size in mice decreased residual feed intake, which is an indicator of a lower body buffer capacity [21]. Also, in a genotype by environmental interaction experiment, an increased environmental sensitivity was observed when selecting for high production, i.e. selection for high milk production in dairy cows increased sensitivity to ambient temperatures [22]. Furthermore, in pig populations it has been observed that populations selected for leanness and reduced intake are more sensitive to environmental stressors than some higher feed intake US genetic populations [28].

The characteristics of the newly founded LP line (higher longevity, later reproductive senescence, and lower environmental sensitivity) are traits of interest beyond rabbit production. These traits are also of interest in other parts of animal production and in human science. Recently, there has been an advance in mapping at both the cytogenetic and genetic level [3]. Mapping this line for the reported characteristics could therefore serve as an important contribution to the genetics of aging.

\section{CONCLUSION}

Selecting for reproductive longevity and average reproductive performance successfully delayed reproductive senescence compared to a prolific line. Moreover, the different selection strategies changed the relative priorities of body condition and reproduction when an environmental challenge occurred. Hyper selection for reproductive longevity and an average reproduction 
performance resulted in animals with a lower environmental sensitivity, which might have been mediated by a higher body energy reserve.

\section{ACKNOWLEDGEMENTS}

The Spanish CICYT project AGL 2004-02710/GAN and the Danish Research Council granted the present study.

\section{REFERENCES}

[1] Baselga M., Gómez E., Cifre P., Camacho J., Genetic diversity of litter size traits between parities in rabbits, J. Appl. Rabbit Res. 15 (1992) 198-205.

[2] Beilharz R.G., Luxford B.G., Wilkinson J.L., Quantitative genetics and evolution: Is our understanding of genetics sufficient to explain evolution? J. Anim. Breed. Gen. 110 (1993) 161-170.

[3] Chanty-Darmon C., Urien C., de Rochambeau H., Allain D., Pena B., Hayes H., Grohs C., Cribiu E.P., Deretz-Picoulet S., Larzul C., Save J.C., Neau A., Chardon P., Rogel-Gaillard C., A first-generation microsatellite-nased integrated genetic and cytogenetic map for the European rabbit (Oryctolagus cuniculus) and localization of angora and albino, Anim. Genet. 37 (2006) 335-341.

[4] Estany J., Baselga M., Blasco A., Camacho J., Mixed model methodology for the estimation of genetic response to selection in litter size of rabbits, Livest. Prod. Sci. 21 (1989) 67-75.

[5] Estany J., Villalba D., Tibau J., Soler J., Babot D., Noguera J.L., Correlated response to selection for litter size in pigs: I. Growth, fat deposition, and feeding behaviour traits, J. Anim. Sci. 80 (2002) 2556-2565.

[6] Falconer D.S., Mackay T.F.C., Introduction to Quantitative Genetics, 4th edn., Longman Group Ltd, Essex, 1996.

[7] Friggens N.C., Body lipid reserves and the reproductive cycle: towards a better understanding, Livest. Prod. Sci. 83 (2003) 219-236.

[8] García M.L., Baselga M., Estimation of genetic response to selection in litter size of rabbits using a cryopreserved control population, Livest. Prod. Sci. 74 (2002) 45-53.

[9] Grandinson K., Rydhmer L., Strandberg E., Solanes F.X., Genetic analysis of body condition in the sow during lactation, and its relation to piglet survival and growth, Anim. Sci. 80 (2005) 33-40.

[10] Groeneveld E., PEST user's manual, Institute of Animal Husbandry and Animal Behaviour, FAL, Germany, 1990.

[11] Holl J.W., Robison O.W., Results from nine generations of selection for increased litter size in swine, J. Anim. Sci. 81 (2003) 624-629.

[12] Kirkwood T.B.L., Rose M.R., Evolution of senescence: late survival sacrificed for reproduction, Phil. Trans. R. Soc. Lond. B, 332 (1991) 15-24. 
[13] Marai I.F.M., Habeeb A.A.M., Gad A.E., Rabbits' productive, reproductive and physiological performance traits as affected by heat stress: a review, Livest. Prod. Sci. 78 (2002) 71-90.

[14] Nagai J., Lin C.Y., Sabour M.P., Lines of mice selected for reproductive longevity, Growth Develop. Aging 59 (1995) 79-91.

[15] Partridge L., Fowler K., Direct and correlated responses to selection on age at reproduction in Drosophila melanogaster, Evolution 46 (1992) 76-91.

[16] Pascual J.J., Blanco J., Piquer O., Quevedo F., Cervera C., Ultrasound measurements of perirenal fat thickness to estimate the body condition of reproducing rabbit does in different physiological status, World Rabbit Sci. 2 (2004) 7-22.

[17] Piles M., García M.L., Rafel O., Ramon J., Baselga M., Genetics of litter size in three maternal lines of rabbits: Repeatability versus multiple-trait models, J. Anim. Sci. 84 (2006) 2309-2315.

[18] Pryce J.E., Coffey M.P., Simms G., The relationship between body condition score and reproductive performance, J. Dairy Sci. 84 (2001) 1508-1515.

[19] Quevedo F., Adecuación de la nutrición a la mejora genética de la coneja reproductora, Doctoral Thesis, February 2005, Universidad Politécnica de Valencia, Spain.

[20] Ramon J., Rafel O., 1991-2000. Diez años de gestión global en España, II Congreso Internacional de Producción y Sanidad Animal, Barcelona 2002, pp. 113-117.

[21] Rauw W.M., Knap P.W., Verstegen M.W.A., Luiting P., Food resource allocation patterns in lactating females in a long-term selection experiment for litter size in mice, Genet. Sel. Evol. 34 (2002) 83-104.

[22] Ravagnolo O., Miztal I., Genetic Component of Heat Stress in Dairy Cattle, Parameter Estimation, J. Dairy Sci. 83 (2000) 2126-2130.

[23] Reznick D., Nunney L., Tessier A., Big houses, big cars, superfleas and the costs of reproduction, Trends Ecol. Evol. 15 (2002) 421-425.

[24] Roff D.A., Life History Evolution, Sinauer Associates, Sunderland, 2001.

[25] Rose R.M., Evolutionary Biology of Aging, Oxford University Press, 1991.

[26] Sánchez J.P., Análisis genético de la longevidad en conejas de producción cárnica. Constitución y evaluación de una línea longevo-productiva de conejos, Ph.D. Thesis, Universidad Politécnica de Valencia, Valencia, Spain, 2006, 167 p.

[27] Sánchez J.P., Theilgaard P., Mínguez C., Baselga M., Constitution and evaluation of a long-lived productive maternal rabbit line, in 8th World Congress on Genetics Applied to Livestock Production, August 13-18, 2006, Belo Horizonte, MG, Brasil, p. 137.

[28] Schinkel A.P., Richert B.T., Frank J.W., Kendall D.C., Genetic by Environmental Interactions for Pig Growth, Purdue 1999, Swine Day Report, pp. 93-103.

[29] Schlichting C.D., Pigliucci M., Phenotypic evolution: a reaction norm perspective, Sinauer Associates, Sunderland, MA, 1998.

[30] Stearns S.C., Ackermann M., Doebeli M., Kaiser M., Experimental evolution of aging growth, and reproduction in fruit flies, Evolution 97 (2000) 3309-3313.

[31] Szendrö Z.S., Maertens L., Maternal effect during pregnancy and lactation in rabbits (a review), Acta Agraria Kaposváriensis 5 (2001) 1-21. 
[32] Theilgaard P., Prolificacy, reproductive longevity and body reserves in female rabbits examined using selection lines. Ph.D. Thesis, Universidad Polytécnica de Valencia, Spain, 2006, p. 126.

[33] Theilgaard P., Sánchez J.P., Pascual J.J., Friggens N.C., Baselga M., Effect of body fatness and selection for prolificacy on survival of rabbit does assessed using a cryopreserved control population, Livest. Sci. 103 (2006) 65-73.

[34] Yazdi M.H., Lundeheim N., Rydhmer L., Ringmar-Cederberg E., Johansson K., Survival of Swedish Landrace and Yorkshire sows in relation to osteochondrosis: a genetic study, Anim. Sci. 71 (2000) 1-9.

[35] Xiccato G., Trocino A., Sartori A., Queaque P.I., Effect of parity order and litter weaning age on the performance and body energy balance of rabbit does, Livest. Prod. Sci. 85 (2004) 239-251.

To access this journal online: www.edpsciences.org 